\title{
A Survey of Acceptance of e-Government Services in the UK
}

\author{
Priti Adeshara ${ }^{1}$, Radmila Juric ${ }^{2}$, Jasna Kuljis ${ }^{3}$ and Ray Paul ${ }^{3}$ \\ ${ }^{1}$ Castell Safety International Ltd., London, UK \\ ${ }^{2}$ Cavendish School of Computer Science, Department of Information Systems, University of Westminster, London, UK \\ ${ }^{3}$ Department of Information Systems and Computing, Brunel University, West London, UK
}

\begin{abstract}
This paper gives an insight into the readiness of Small and Medium Sized Enterprises (SMEs) for accepting e-government services in the UK. We conducted a survey of 128 SMEs, which revealed that there is a moderate demand for e-government services, but they were not rated as efficient and essential for SMEs' businesses as conventional services. The proliferation of the UK government's websites, which requires co-ordination between several organisations/multiple sites, and inadequate awareness of such services, do not comply with the common concepts of e-governance and, consequently, have an impact on the SMEs acceptance of e-government services in the UK.
\end{abstract}

Keywords: e-government services, SME.

\section{Introduction}

Advances in Information and Communication Technologies (ICT) have challenged governments all over the world to innovate their traditional structures and consider e-enabled approaches for the implementation of effective public service delivery and for improved performance within public administration. Some e-government initiatives aim to build services focused on citizens' needs $[12,5,19,23]$. However, e-government is more than a citizen service using the latest ICT. It involves new forms of delivering and tailoring information and services, linking communities and businesses locally and globally and streamlining us towards digital democracy $[7,16,20,10]$. The application domain of such multiple administrative services and systems has distinguished characteristics classified through: (a) the four different perspectives that shape egovernments: the citizen's perspective, process re-design perspective, telecooperation and knowledge perspectives [15];

(b) a framework supported by three dimensional views of e-governments: institution, service and relation-based views [9] and

(c) the common concepts of e-governance [19] which may

(i) have multiple parties involved: citizens, intergovernmental agencies and enterprises,

(ii) need a "one-stop shop services" for each party,

(iii) redesign organisational processes within government bodies and

(iv) create domain knowledge which enables citizens and businesses to act according to legislations and standards.

Consequently, e-government services extend towards businesses and their improved relationships with administration and citizens. Very flexible and fast access to public agencies through the Internet saves time and money of businesses from all industries sectors in their internal and external administrative and financial dealings [1]. Nurturing e-readiness of various industry sectors $[3,4]$ and streamlining them towards e-government services has become a major initiative $[13,29]$.

If we recognize that approximately $80 \%$ of economic growth comes from SMEs and that $95 \%$ of all businesses in North America and Europe 
are SMEs $[13,6]$, then government's strategies on supporting the e-readiness of SMEs and SMEs' acceptance of e-government services are becoming more important. Easy access to eservices is of tremendous value to SMEs. They are very vulnerable and have special needs because of their limited resources, pressures arising from e-commerce applications and forces of global competitions. Consequently, the UK government initiatives towards SMEs are numerous and range from e.g. action plans “...for making the UK the best place to start and grow business" [25], to information on strategies for building e-government services for public sector and businesses [27].

The purpose of this paper is twofold:

1. to inspect UK government web sites and assess their 'e-service readiness' for SMEs, which is given in section 2 and

2. to investigate the readiness of the UK SMEs to accept e-government services, which is given in section 3 .

For 1 above, we assessed how close the UK concepts for e-governance are to the common concepts stated in (c) above. We also obtained some research results that highlight the UK government web sites' accessibility and conformity to the Web Content Accessibility (WCA) guidelines provided by $\mathrm{W} 3 \mathrm{C}[30,21]$. For 2 above, we conducted a survey in 2003 , by sending a questionnaire to 2200 UK SMEs. The response rate of $5.8 \%$ gave us an insight into 128 SMEs and their attitudes towards the acceptance of egovernment services. The results of the survey are in section 3.1. Section 4 gives conclusions and recommendations.

\section{The UK Government's Web Sites}

The vast information and number of the UK egovernment services are scattered across multiple web sites, whose selection is given in the Appendix, Figure 1. The more SME specific information is located on the Small Business Services (SBS) web site http://www. sbs .gov.uk/. This web site includes direct links towards sources relevant to SMEs, which are listed in the first column of table 3 in the Appendix. However, in our first attempt to allocate the SME specific web sites, a search engine did not direct us towards the SBS, but towards UK Online [26], which is a UK government portal. UK Online gives an understanding what e-commerce and e-business can mean to SMEs and offers

- advice to all companies, ranging from those with no current use of ICT to specialist multimedia hardware and software developers (160,000 SMEs were helped in 2002),

- a range of free UK Online For Business publications on various technologies to explain the IT jargon that can be alienating to nontechnical people.

The backbone of UK Online For Business is a network of advisers who are part of Business Link in England and their counterparts in Scotland, Wales and Northern Ireland [24]. They claim to provide advice suited to local companies' needs including e-commerce services, ranging from direct company-specific assistance, to some training and consultancy.

It is obvious that the UK e-government services do not follow all of the common concepts of e-governance stated in (c) from section 1 and that the "one-stop shop services" ( section 1 (c) (ii)) for SMEs does not exist. It is very difficult to find a coherent source, which contains both information and services tailored for SMEs.

In 1999, the UK government released its first set of guidelines for all government websites, formally setting out the standards for quality, content and design of sites. They included

- Specifications for the links that should be included from sites' home pages;

- The need to have no-frames versions of sites that use frames;

- Basic types of information that all government departments should provide on their sites.

However the UK government web sites still fail to comply to metadata standards that make it easier to manage and find information on a web-site [17]. Only seven web sites complied fully with WCA [30], and the site dedicated for businesses, UK Online [26], had the slowest response time. 


\section{The Survey of the SMEs Acceptance of e-Government Services}

The presence of extensive information, aimed at SMEs, on adopting the ICT and e-commerce, highlights the UK government's initiative in providing a partnership between business, government and the wider community, underpinned by a complete modernisation of the government [22]. The emphasis is on encouraging SMEs' success in implementing technology advances and successfully competing locally and globally. This is also considered as a vital drive to transform online businesses in the UK. Despite various research showing a positive impact of broadband technology for SMEs, regional differences in the UK SMEs' access to broadband mirror the 'digital divide' effect in our society, with London and South East being the key beneficiaries [6]. In the light of these findings, our survey included only a few initial questions on SMEs' access to the Internet and broadband technology, in order to verify our results with the available national statistics from [18]. Consequently, 17 of 21 questions in our survey were related to the readiness of the SMEs to adopt e-government services. We expected that the survey would reveal

1. how big the demand for e-government services is;

2. how much e-government services are effective for or useful to SMEs;

3. which e-government services are used by SMEs and which are the most attractive to SMEs;

4. which problems SMEs experience when using e-government services.

The questionnaire, which consisted of a list of 21 pre-set questions, was available for completion online. It was posted on the author's homepage and sent as a link to the company's email address along with a cover letter explaining the purpose of the study. For those not wishing to take part in a full survey, but who may have wished to provide some general thoughts, a feedback form was also available for completion online. A sample of 2200 businesses was selected to be representative of the range of business sizes and industry (a turnover of not more than 5.6 million and not more than 350 employees). The sample was selected from two sources: Kompass Directory, '2000 UK Companies' [13] and Financial Times 'Top 500 UK companies' [8] (using 200 of those that fit in with the above definition of SMEs). In early July 2003 , the questionnaire was e-mailed to either information technology directors or directors of the companies. The cut off date was set to 5-9-2003. We received 128 responses $(5.8 \%)$.

\subsection{Results}

Forty percent of companies that participated in our survey used a broadband technology, 20\% did not have broadband, but used the Internet, and $26 \%$ of them had no internet access at all. Only $59 \%$ of the internet users had their own PC, $15 \%$ of them used libraries, $11 \%$ of them used Internet Cafés and 5\% mobile phones. The biggest concerns with the use of the Internet were inaccurate information $(25 \%)$, potential violation of security (24\%) and cost (20\%). These results correspond to the National Statistics Omnibus data [8] which includes "key factors on the Internet and Web use in the UK".

Questions on e-government services from our survey provided the following results, and addressed the issues from 1-4 in section 3:

Demand for e-government services: only $56 \%$ of companies have used e-government services for their business needs and $64 \%$ of them think that e-government services adhere to their business needs.

Effectiveness of e-government services: a striking $46 \%$ of companies think that e-government services are NOT very effective for their business, $20 \%$ think that they are not effective at all and only $13 \%$ agree on government e-service effectiveness.

Dependency on e-government services: only $9 \%$ of companies are very dependent on egovernment services, $24 \%$ not very dependent and $49 \%$ think that they are not dependent at all! Furthermore, they do not regularly visit government's web sites: $29 \%$ do it rarely, $21 \%$ weekly and $13 \%$ daily.

Awareness of e-government services: $38 \%$ of companies became aware of the government web sites and e-government services through 
a search engine and $24 \%$ were linked to egovernment services through other web sites. $14 \%$ were informed about e-government services through word of mouth, $6 \%$ through post, and $6 \%$ through $\mathrm{TV}$.

Rating of e-government services: $55 \%$ of SMEs think that they are below average, and $15 \%$ think that they are the same as offline services. Only $20 \%$ think that they are above average.

Problems: issues of concern and financing: $28 \%$ of companies were most concerned about security of transaction through government services, $21 \%$ about the violation of privacy, $21 \%$ about speed and ease of use of services and $20 \%$ were concerned about the cost of services. $48 \%$ of companies think that e-government services should be financed from general taxes paid by everyone, $24 \%$ would like to have a limited web site banner advertising and $14 \%$ would agree on selling access on an annual subscription basis.

Additional results are given in tables 2, 3, 4 .

\section{Conclusion}

There is a demand for e-government services amongst UK SMEs, but the percentage of companies using them is still moderate. The most frequently used e-government services are Online legal advice, Self assessment tax return, Improve your business, Training, Development and Writing a business plan and Grants and support schemes. However, a striking $46 \%$ of SMEs stated that e-government services as a whole are not very effective for their businesses and only $9 \%$ of SMEs are dependent on them. A small number of SMEs visit the e-government web sites daily and awareness of the e-government services existence is very low! Furthermore, e-government services were rated 'below average', compared with the same offline services by $55 \%$ of SMEs.

These results are surprising, but explanations for them might lie along the following lines:

- The Internet is still used by slightly more than half of the UK SMEs [18, 26].

- SMEs in general lack resources to keep track, analyze and introduce regular changes into their business processes which incorporate e-government services [28, 2].

- SMEs are unwilling to pay for the private sector training services based on market rates, and improve their acceptance of ICT, ebusinesses and e-government service [26]. They claim that they experience a lack of external support in addressing all these issues from governments, banks, and ICT providers (i.e. there are no financial incentives). However, there is the government imitative available at [24] - see section 2 - which is not taken up by SMEs!

- There exists a "...British scepticism towards the state" [11] and some family-controlled SMEs are reluctant to disclose any financial information to outsiders.

- The sheer proliferation of the UK government's websites is a problem: more than 800 government bodies have spawned over 3000 sites, according to the House of Common public accounts committee [18]. Many transactions require co-ordination between several organisations and visits to multiple sites. We have experienced the same problem when searching for SMEs'-tailored websites.

Adhering to the common concepts of e-governance from (c) in section 1 could definitely help to alleviate all these problems and might be the only way forward towards SMEs' readiness to accept e-government services. SMEs will access government services online only if doing so is quicker, easier, cheaper than, and as reliable as going through conventional channels. The UK government should also consider how to increase SMEs' awareness of e-services and their benefits by advertising them through the printed and broadcast media.

At the time of writing this paper we were not aware of any similar study or survey undertaken in the UK or elsewhere, hence we could not compare our results with the e-readiness of SMEs from any other western economies. 


\section{Appendix}

Department for Education and Skills:

UK Business Link:

DTI:

Patent Office:

Companies House:

Trade Partners:

Direct Access Government for Business:

HM Customs and Excise:

Inland Revenue:

UK Online for Business:

Employment relations information:

Criminal Records Bureau for organizations:

Applications for export licenses:

Corporation tax:

Information on health and safety legislation:

Order and pay for key company information:

Send and receive a range of PAYE form:

Company Registration (Incorporation):

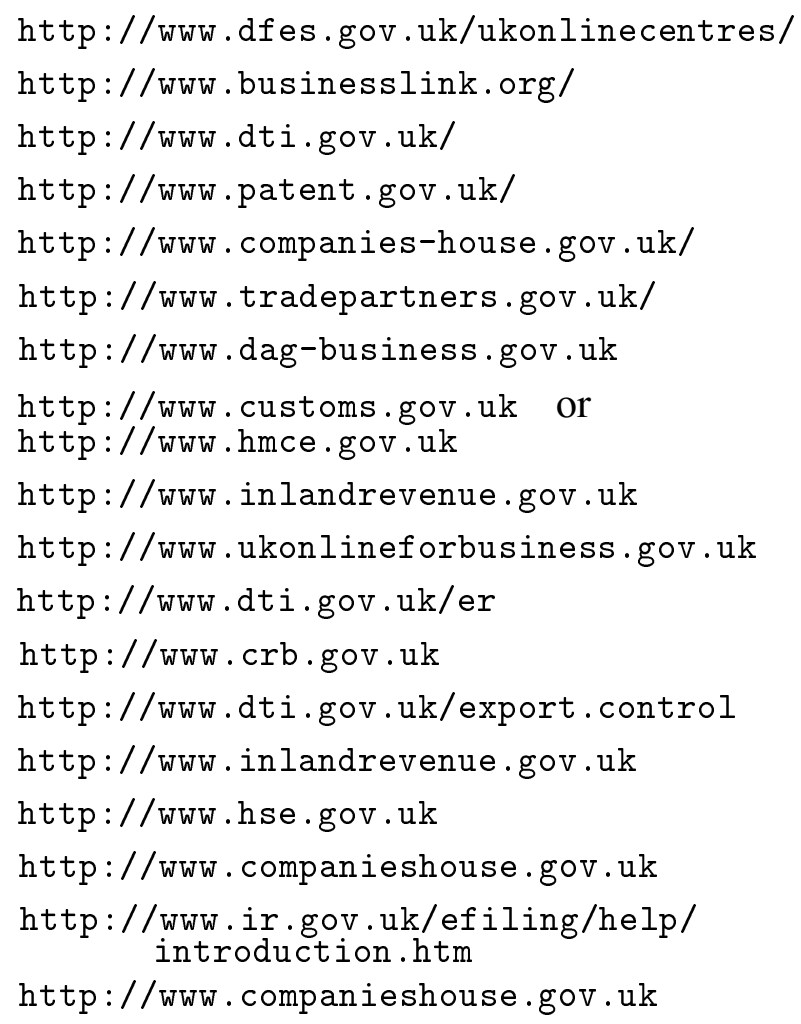

Table 1. A Selection of UK Government Web Sites.

Company directors indicated they are not interested in e-government $\quad 13 \%$

Company directors do not view e-government as a high priority $15 \%$

Expenses for e-government are too high given our other needs $10 \%$

$\begin{array}{ll}\text { We are not sure where to begin } & 2 \%\end{array}$

We do not have access to high-speed telecommunications lines, $\quad 12 \%$

or other infrastructure

We do not have the computers, software,

or other necessary equipment

$\begin{array}{ll}\text { Staffs do not have e-government background or training } & 12 \%\end{array}$

$\begin{array}{ll}\text { We are unable to keep up with rapidly changing technology } & 10 \%\end{array}$

Government services don't adhere to our needs on online $12 \%$ 
Help for small businesses

Information $\%$

Improve your business

Performance

Expand your business

Innovation and technology

Help with environmental matters

Help with regulations

Help with European matters

Help for Trade Association

Trade and Investment

Online legal advice

Self assessment tax returns

Writing a business plan

Grants and support schemes
10

21

6

Services $\%$

Both \%

17

13

24

6

5

12

12

18

11

27

4

12

16

0

0

19

2

$\begin{array}{lll}6 & 14 & 21\end{array}$

$\begin{array}{lll}4 & 5 & 24\end{array}$

36

$58 \quad 41$

45

$62 \quad 56$

21

18

28

12

5

26

Table 3. Percentage of online information and services that have been used by SMEs.

Government, Politics

Information, Communication

People, Communities

Business \& Industry

Agriculture, Environment

International Affairs \& Defence

Crime, Law, Justice \& Rights

Education, Careers

Economics, Finance

Science Technology

Arts, Recreation \& Travel

Health, Nutrition \& Care
On line \%

5

16

8

7

4

10

3

2

25

2

8

4
Off line \%

9

7

10

16

5

6

7

3

20

10

2

0

Table 4. Sectors indicated by SMEs that need SIMPLIFIED government administrative procedures. 


\section{References}

[1] AichHolzer G., SPERLiCH R., Electronic Government Services for the Business Sector in Austria, $12^{\text {th }}$ Int. Workshop on Database and Expert Systems Applications, IEEE Computer Society 2001, ISN 0-7695-1230-5, pp. 412-416;

[2] Al-QIRIM, N., CORBITT B. J., E-Business, eGovernment \& Small and Medium Sized Enterprises: Opportunities and Challenges, IGP, ISBN 1-59140-264-6, 2003.

[3] Bridges.org, E-readiness Assessment: Who is doing What and Where, 2003, available at http://www . bridges.org/ereadiness/where.html.

[4] BRown L. C., G-8 Collaborative Initiatives and the Digital Divide: Readiness for e-Government, $35^{\text {th }}$ HICSS, 2002 IEEE, ISN 0-7695-1435-9/02.

[5] Csetenyi A., Electronic Government: Perspectives from E-Commerce, $11^{\text {th }}$ Int. conf. on Database and Expert Systems Applications, 2000 IEEE, ISN 0-7695-0680-1/00, pp. 294-298.

[6] Dixon, T., Thompson B., And McAllister, P., The Value of ICT for SMEs in the UK: A Critical Literature Review, report for Small Business Service Research Program, The College of Estate Management in Reading, UK; available also at http://www.sbs.gov.uk/default.php?page= /analytical/publicationsbytheme.php.

[7] Elgamarid A. K., McIver, W. J., The Ongoing March Towards Digital Government, in IEEE Computer, February 2001, pp. 32-38.

[8] Financial Times - Top 500 UK Companies, http: //www.ft.com/ft500.

[9] GiSLER M., D. SPAHNI, e-Government Experiences of the Swiss Federal Institute for Intellectual Property $11^{\text {th }}$ Int. conf. on Database and Expert Systems Applications, 2000 IEEE, ISN 0-7695-0680-1/00, pp. 278-281.

[10] GRONLUND A., Democracy in an IT-Framed Society, in CACM, January 2001, pp. 23-26.

[11] HEATH, W., Europe's Readiness for E-government, 2002 available at http: //www . dad . be/ library/pdf/kable.pdf.

[12] JACKSON P., CURTHOYS N., E-Government: Developments in the US and UK, $12^{\text {th }}$ Int, Workshop on Databases and Expert Systems Applications, Germany, 2001 IEEE ISN 1529-4188/01, pp. 334-342.

[13] Jutla D., Bodorick P., AND DHALiwal, J., Government Support for the e-Readiness of Small and Medium Sized Enterprises, $35^{\text {th }}$ HICSS, 2002 IEEE, ISN 0-7695-1435-9/02.

[14] Kompass Directory, http://www.kompass.co.uk/.
[15] LENK K., R. TRAunMuller, A Framework for Electronic Government, $11^{\text {th }}$ Int. conf. on Database and Expert Systems Applications, 2000 IEEE, ISN 0-7695-0680-1/00, pp. 271-277.

[16] Marchionini G., Samet, H., Brandt L., (Eds.) Digital Government, CACM, January 2003, pp. 25-27.

[17] McCuE A., Government sites fail web accessibility and standards test, available at http://www . silicon. com/networks/webwatch.

[18] OMNIBUS available at http://www.sbs.gov. uk/default .php?page=/analytical/ publicationsbytheme.php.

[19] Papantoniou, A., Hattab, E., Afrati, F., KayAFAS, E., Loumos V., Change Management, a Critical Success Factor for e-Government, $12^{\text {th }} \mathrm{Int}$, Workshop on Databases and Expert Systems Applications, Germany, IEEE 2001, ISN 1529-4188/01, pp. 402-406.

[20] SCHERLIS W. L., EISENBERG J., IT Research, Innovation, and E-Government, CACM January 2003, pp. 67-69.

[21] SouZA R. AND H. MANnING, The Web Accessibility Time bomb, Forrester Research Technology Strategy Report 2000, http: //www. forrester.com/ Research/List.

[22] Survey: government and the internet: No gain without pain; Why the transition to e-government will hurt, 22-6-2000, from The Economist print edition available at http://www.economist.com/ surveys/displayStory. cfm?Story_id $=80764$.

[23] UK Cabinet Office e-Government: A Strategic Framework for Public Services in the Information Age: Modernising Government, available at http: //www . iagchampions . gov .uk/Strategy.htm.

[24] UK: Business Link Practical help and advice for businesses, managed by DTI and available at http: //www.businesslink.gov.uk/bdotg/ action/home.

[25] UK Small Business Services: A Government Action Plan for small businesses, available at http: //www.sbs.gov.uk/sitehelp/sitemap.php.

[26] UK Online - UK Government portal http: //ukonlne.gov.uk.

[27] UK Online - Strategy the Government's Comprehensive Programme to Lead the Knowledge Economy Revolution, and How the Strategy is Managed, available at http://www.e-envoy . gov.uk/EStrategy/EStrategy/fs/en.

[28] Department of Trade and Industry (DTI): Opportunity for all in the world of change, available at http: //www.dti.gov.uk/.

[29] WASSENAAR A., (2000) E-Governmental Value Chain Models, $11^{\text {th }}$ Int. conf. on Database and Expert Systems Applications, 2000 IEEE, ISN 0-7695-0680-1/00, pp. 289-293.

[30] WCA: Web Content Accessibility, http: //www . w3. org/TR/WAI-WEBCONTENT/. 
Received: June, 2004

Accepted: June, 2004

Contact address

Priti Adeshara

Castell Safety International Ltd.

217 Kingsbury Road

London NW9 9PQ, UK

e-mail: padeshara@castell.co.uk

Radmila Juric

Cavendish School of Computer Science

Department of Information Systems

University of Westminster

115 New Cavendish Street

London W1W 6UW, UK

e-mail: juricr@wmin.ac.uk

Jasna Kuljis

Ray Pau

Department of Information Systems and Computing

Brunel University

West London

Middlesex UB8 3PH, UK

e-mail: Jasna.Kuljis@brunel.ac.uk

Ray.Paul@brunel.ac.uk

PRITI ADESHARA obtained her BSc degree in product engineering and $\mathrm{MSc}$ in information systems from the University of Westminster, UK. Her research interests include web technologies/services, e-commerce, e-governments/portals and governmental initiatives for SMEs. She hopes to further her knowledge in this field by undertaking further study for her $\mathrm{PhD}$. She is currently employed as a Procurement Officer at Castell Safety.
RADMILA JURIC is a principal lecturer at Cavendish School of Computer Science at the University of Westminster, UK. She was educated at the University of Zagreb and University of London. Her teaching, research and publications include fields of information systems and software engineering (UML, CASE tools, requirements engineering, component-based software architectures, healthcare informatics, education) and databases (DB reverse engineering, migration between DB technologies, interoperability amongst DB environments and repositories).

JASNA KULJIS is a Reader in the Department of Information Systems and Computing at Brunel University. She gained her Dipl.Ing. degree in theoretical mathematics from the University of Zagreb, Croatia. She gained her M.S. in information science from the University of Pittsburgh, USA, and a Ph.D. in information systems from the London School of Economics, University of London. Her current research is in human computer interfaces. She is mostly interested in the design of graphical user interfaces and in the development of new paradigms that would further enhance the usability of interactive computer systems. She is Director of the VIVID Research Centre at Brunel University. Dr. Kuljis' email and web addresses are jasna.kuljis@brunel.ac.uk and www. brunel.ac.uk/ csstjjk, respectively.

RAY PAUL is a Professor Associate in the Department of Information Systems and Computing (DISC) at Brunel University, and Visiting Professor in the Department of Information Systems at the London School of Economics (LSE). Ray taught operational research and information systems at LSE for 21 years, then joined Brunel for 12 years before retiring early on the grounds of permanent ill-health - he has Parkinsonism. Ray has over 300 refereed publications and 3 books. He is co-editor of the European Journal of Information Systems, which he co-founded in 1990. He is one of the Editors of the Journal of Computing and Information Technology, a post he is proud to have held since the start of the journal. Ray's research interests are in business modelling, particularly simulation, and information systems development. He has held over $£ 1.5 \mathrm{~m}$ in U.K. government grants in the last few years and collaborates with a vast array of international talent too numerous to mention, exemplified by his holding an Honorary Professorship in Community Medicine at Hong Kong University a few years ago. 